\title{
Autoantibodies against insulin-like growth factor-binding protein-2 as a serological biomarker in the diagnosis of lung cancer
}

\author{
YING ZHANG ${ }^{1}$, XIA YING ${ }^{1}$, SUXIA HAN ${ }^{1}$, JING WANG ${ }^{1}$, XIA ZHOU $^{1}$, \\ E BAI $^{1}$, JIANYING ZHANG ${ }^{1,2}$ and QING ZHU ${ }^{1}$ \\ ${ }^{1}$ Department of Oncology, The First Affiliated Hospital of Xi'an Jiao Tong University Medical Center, \\ Xi'an, Shaanxi 710061, P.R. China; ${ }^{2}$ Department of Biological Sciences, \\ The University of Texas at El Paso, El Paso, TX 79968, USA
}

Received September 12, 2012; Accepted October 26, 2012

DOI: $10.3892 /$ ijo.2012.1699

\begin{abstract}
Insulin-like growth factor-binding protein-2 (IGFBP-2) is considered to be a human tumor antigen, and the tumor-specific immunity of IGFBP-2 has been reported in several types of cancer. The purpose of this study was to evaluate whether autoantibodies to IGFBP-2 can be used as diagnostic markers in lung cancer. The results demonstrated that serum anti-IGFBP-2 autoantibody levels were significantly elevated in lung cancer (mean, 1,633.318 ng/ml; median, 1,651.462 ng/ml; range, $342.732-4932.582 \mathrm{ng} / \mathrm{ml}$ ) compared with benign lung disease $(1,210.139,1,035.900,547.596-2,331.167 \mathrm{ng} / \mathrm{ml})$ and normal controls $(1,303.369,1,194.800,528.200-2140.500 \mathrm{ng} / \mathrm{ml})$. The sensitivity and specificity of anti-IGFBP-2 autoantibodies in diagnosing lung cancer was 73.2 and $60.6 \%$, respectively. When serum IGFBP-2 and anti-IGFBP-2 autoantibody were used together in the diagnosis of lung cancer, it can increase the discriminative power for lung cancer with a sensitivity of $85.7 \%$ and a specificity of $57.5 \%$. In conclusion, this study
\end{abstract}

Correspondence to: Dr Qing Zhu, Department of Oncology, The First Affiliated Hospital, Xi'an Jiaotong University Medical College, Xi'an, Shaanxi 710061, P.R. China

E-mail: newzhuqing1972@yahoo.com

Abbreviations: IGFBP-2, insulin-like growth factor-binding protein-2; $\mathrm{CT}$, computed tomography; TAAs, tumor-associated antigens; IGFs, insulin-like growth factor family; CEA, carcinoembryonic antigen; CYFRA21-1, cytokeratin 19 fragments; NSE, neuron-specific enolase; IHC, immunohistochemical analysis; ELISA, enzymelinked immunosorbent assay; IgG, intravenous gamma globulin; BSA, bovine serum albumin; PBS, phosphate-buffered saline; HRP, horse radish peroxidase; TMB, tetramethylbenzidine; $\mathrm{H} 2 \mathrm{SO} 4$; OD, optical density; ROC, receiver operating characteristic; AUC, area under the curve; PI3K, phosphatidylinositol 3-kinase; Akt, serine-threonine kinase; PTEN, phosphatase and tensin homolog deleted on chromosome ten; ERK, extracellular signal-regulated kinase

Key words: autoantibody, insulin-like growth factor-binding protein-2, biomarker, diagnosis, lung cancer demonstrates that circulating anti-IGFBP-2 autoantibodies can be used as a potential biomarker in diagnosing lung cancer.

\section{Introduction}

Lung cancer has become the most common malignant tumor and the major cause of cancer deaths worldwide. The overall 5 -years survival rate for lung cancer is only $15 \%$ (1). The largest gain in life expectancy in lung cancer patients has been among those with localized disease versus those with regional or distant metastasis. However, due to the asymptomatic nature of the early disease and the lack of effective screening methods, only $19 \%$ of lung cancers are localized at the time of diagnosis (2). Although there has been significant progress in diagnostic tools at clinics including CT (computed tomography) scans, bronchoscopy and sputum analysis, none of these turns out to be an effective tool in early diagnosis of lung cancer. How to establish a methodology to identify the high-risk individuals for lung cancer remains to be investigated.

Cancer has long been recognized as a multi-step process which involves not only genetic changes conferring growth advantage but also factors which disrupt regulation of growth and differentiation. It is possible that some of these factors could be identified and their functions evaluated with the aid of autoantibodies arising during tumorigenesis. The heterogeneity in the molecular pathogenesis of human cancers must be taken into account in both the design and interpretation of studies to identify makers which will be useful for early diagnosis of cancer. Many studies have demonstrated that the cancer cells can generate a unique set of antigenic change which can be recognized by the immune system of patients themselves. These antigens are called tumor-associated antigens (TAAs), whose abnormal regulation or excessive expressed are closely related to tumorigenesis (3). The appearance of circulating autoantibodies against these TAAs is one of the important ways which are manifested by cancer patient's immune system $(4,5)$. These anti-TAA autoantibodies can magnify the signal when the tumor antigen expression is very low even when it is not able to be detected, suggesting that these autoantibodies may 
be reporters identifying aberrant cellular mechanisms in tumorigenesis and also served as immunodiagnostic markers for cancer detection, especially because of the general absence of these antoantibodies in normal individuals and non-cancer conditions. For example, autoantibodies to TAAs such as p53 and p16 were detected in 10-20\% of most type of cancer patients $(6,7)$, while autoantibodies to $\mathrm{p} 62$ were $21 \%$ positive in patients with hepatocellular carcinoma (8). Due to the fact that these autoantibodies do not exist or appear with a very low titer in the serum samples of healthy people, therefore, the autoantibodies may become potential biomarkers in the diagnosis of certain type of cancer.

Insulin-like growth factor-binding protein-2 (IGFBP-2) is one member of the insulin-like growth factor family (IGFs), and recently reported to be a tumor-associated antigen (9). IGFBP-2 is overexpressed in a majority of malignant tumors, including glioma (10) and colorectal $(11,12)$, prostate $(13)$, ovarian (14) and breast cancers (15). Although overexpressed IGFBP-2 is associated with increased tumor stages and grades (12), relapse, metastasis (14) and prognosis (16) in advanced cancers, it is less satisfactory in diagnosing early cancers. A recently published paper (17) first demonstrated that serum anti-IGFBP-2 antibody was significantly elevated in gliomas and colorectal carcinoma, suggesting that the detection of circulating anti-IGFBP-2 antibody may be a potential approach in diagnosing early cancers. In the current study, we aimed to evaluate whether serum IGFBP-2 and anti-IGFBP-2 antibody can be used as biomarkers in detection of lung cancer.

\section{Materials and methods}

Patients and samples. Blood samples (n=294) were prospectively collected from consented individuals under an Institutional Ethics Committee-approved study from the First Hospital of Xi'an Jiaotong University for patients with lung cancer $(n=190$; 55 lung cancers stage I-II and 135 lung cancers stage III-IV), from 2011 to 2012. In addition, 9 patients also consented to a follow-up evaluation of anti-IGFBP-2 antibodies. Sera from six patients with lung cancer were collected after surgery and chemotherapy, and sera from three patients were also collected after each cycle of chemotherapy. As control, sera from patients with benign lung disease such as phthisis, pneumonia and hamartoma $(n=33)$ were obtained from individuals from the same hospital who were having annual health examinations and had no evidence of malignancy ( $n=71$, see Table I).

The blood was drawn before surgery, chemotherapy or radiotherapy, blood samples were separated by centrifugation at 2,500 rpm for $8 \mathrm{~min}$ and stored at $-80^{\circ} \mathrm{C}$ until further analysis. Electrochemical luminescence kits (Roche, Mannheim, Germany) were used to measure serum levels of carcinoembryonic antigen (CEA), cytokeratin 19 fragments (CYFRA21-1) and neuron-specific enolase (NSE) in 138 patients (98 lung cancer, 17 lung benign disease and 23 controls, see Table II). Cutoff values for CEA, CYFRA21-1 and NSE were 3.4, 3.3 and $15.2 \mathrm{ng} / \mathrm{ml}$, respectively, used by the First Hospital of $\mathrm{Xi}$ 'an Jiaotong University. The same sera were also used for IGFBP-2 and anti-IGFBP-2 antibody measurement. Immunohistochemical analysis (IHC) of IGFBP-2 expression was performed on tissue specimens, collected during surgical operation.
Indirect ELISA for serum IgG antibodies against IGFBP-2. Serum IgG antibody against IGFBP-2 was assessed by indirect enzyme-linked immunosorbent assay (ELISA) as previously described (17). Briefly, Immulon 4HBX microtiter plates (Dynex), were coated overnight (at least for $24 \mathrm{~h}$ ) with $50 \mu \mathrm{l}$ of highly purified, human recombinant IGFBP-2 protein (R\&D Systems Inc., Minneapolis, MN) diluted in $50 \mathrm{ml}$ carbonate buffer (Sigma-Aldrich Corp., St Louis, MO) to a concentration of $1.0 \mu \mathrm{g} / \mathrm{ml}$ or carbonate buffer alone in alternating columns. The last column of wells was incubated with $50 \mu 1$ per well of serially diluted, purified human $\operatorname{IgG}(25,100,250,500,1,000$ and 2,000 $\mathrm{ng} / \mathrm{ml})(\mathrm{R} \& \mathrm{D}$ Systems Inc.) to provide a standard curve.

Plates were blocked with $5 \%$ bovine serum albumin (BSA) in phosphate-buffered saline (PBS), $50 \mu \mathrm{l}$ per well, for $2 \mathrm{~h}$ at room temperature, washed four times with PBST (0.1\% Tween-20 in PBS), and then incubated with diluted (1/5) serum in $1 \%$ BSA/PBS, $50 \mu \mathrm{l} /$ well, for $2 \mathrm{~h}$ at room temperature with gentle shaking. Plates were washed 4 times again and $50 \mu \mathrm{l}$ per well of goat anti-human IgG-HRP (Invitrogen Ltd, Paisley, UK) diluted 1:30,000 in 1\% BSA was added and incubated for $1 \mathrm{~h}$ at room temperature. Following four washes, $100 \mu \mathrm{l}$ per well of tetramethylbenzidine (TMB) was added, reaction was stopped by adding $100 \mu \mathrm{l} 2 \mathrm{M}$ sulphuric acid $\left(\mathrm{H}_{2} \mathrm{SO}_{4}\right)$. Plates were then read at $450 \mathrm{~nm}$. The optical density (OD) of each serum dilution was calculated as the OD of the protein-coated wells minus the OD of the buffer-coated wells. The concentration of serum anti-IGFBP-2 antibody was calculated based on the standard curve on each plate.

Direct ELISA for serum IGFBP-2. Serum IGFBP-2 was measured with commercially available IGFBP-2 ELISA kits (RapidBio Laboratory, Calabasas, CA) following the manufacturer's instructions. The concentrations of the IGFBP-2 standards for building a standard curve were $62.5,125,250$, $500,1,000$ and 2,000 ng/ml. Serum was serially diluted.

IHC analysis. IGFBP-2 immunostaining was carried out as described (10). The sections of tumor tissues were immunostained with monoclonal anti-IGFBP-2 antibody (Cell Signaling Technology, Boston, MA). Five most heavily stained fields were chosen to determine the percentage of positive cells. Zero represents no positive, + represents $<10 \%,++$ represents $11 \%-30 \%,+++$ represents $31 \%-60 \%$, and ++++ represents $>60 \%$ positive staining cells.

Statistical analysis. Statistical analyses were carried out using SPSS 13.0. Demographic data were analyzed with $\chi^{2}$ test. The differences of anti-IGFBP-2 antibody and serum IGFBP-2 levels between controls and patients were assessed using a standard non-parametric Mann-Whitney U test. Receiver operating characteristic (ROC) curves were constructed to determine the discriminatory capacity of anti-IGFBP-2 antibodies for diagnosis, and the area under the curve (AUC) was analyzed by $\chi^{2}$ test. Sensitivity was defined as the number of patients with elevated anti-IGFBP-2 antibodies in serum divided by the total number of patients with lung cancer. Specificity was defined as the number of patients without elevated antiIGFBP-2 antibodies in serum divided by the total number of control patients. Correlations of serum anti-IGFBP-2 antibody 
Table I. Characteristics of patients.

\begin{tabular}{lrrrr}
\hline & \multicolumn{2}{c}{$\begin{array}{c}\mathrm{n} \\
\text { (male/female) }\end{array}$} & $\begin{array}{c}\text { Range of } \\
\text { the age } \\
\text { (years) }\end{array}$ & $\begin{array}{r}\text { Mean of } \\
\text { the age } \\
\text { (years) }\end{array}$ \\
\hline Normal controls & 71 & $(49 / 22)$ & $36-77$ & 58.75 \\
Benign lung disease & 33 & $(20 / 13)$ & $34-88$ & 59.94 \\
Lung cancers & 190 & $(138 / 52)$ & $27-82$ & 61.38 \\
Lung cancer I & 21 & $(15 / 6)$ & $42-82$ & 65.67 \\
Lung cancer II & 34 & $(24 / 10)$ & $38-76$ & 59.88 \\
Lung cancer III & 73 & $(53 / 20)$ & $27-82$ & 60.52 \\
Lung cancer IV & 62 & $(46 / 16)$ & $32-78$ & 61.61 \\
Total & 294 & $(207 / 87)$ & $27-88$ & 60.55 \\
\hline
\end{tabular}

Stratifying the analysis by American Joint Committee on Cancer stage for lung cancer.

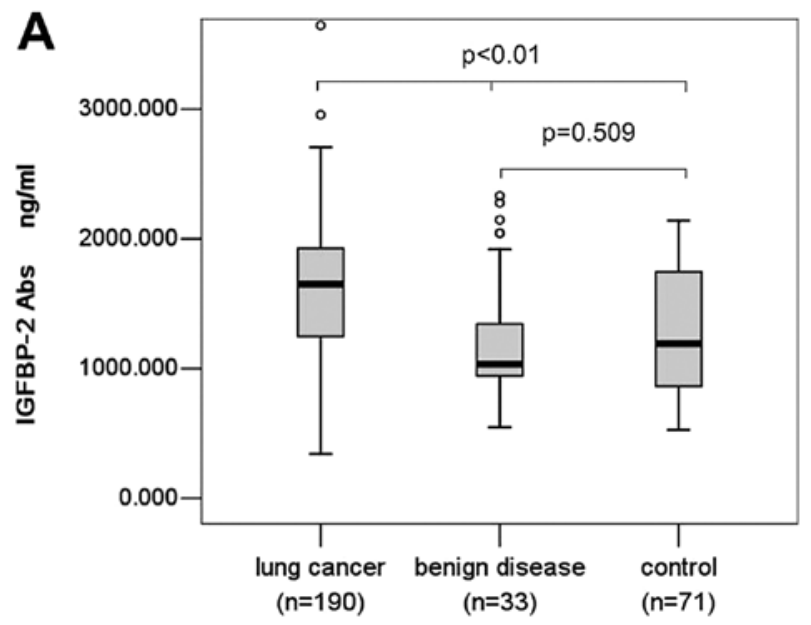

Figure 1. Serum IgG autoantibodies to IGFBP-2. (A and B) Comparisons among normal controls, benign lung disease and patients with lung cancer, and substages. Median levels of serum autoantibodies to IGFBP-2 and interquartile ranges are illustrated by box plot. N, number of subjects; dot, outliers; IGFBP-2, insulin-like growth factor-binding protein-2.

levels with tumor tissue IGFBP-2 expression levels were assessed by Pearson's correlation analysis. The results were considered to indicate a statistically significant difference at p-value $<0.05$.

\section{Results}

Elevated serum anti-IGFBP-2 antibody levels in lung cancer. Serum levels of anti-IGFBP-2 antibodies were determined by ELISA as described in the section of Materials and methods, the study population is summarized in Table I. We found serum anti-IGFBP-2 antibody level of lung cancer patients (mean, $1633.318 \mathrm{ng} / \mathrm{ml}$; median, $1651.462 \mathrm{ng} / \mathrm{ml}$; range, $342.732-4932.582 \mathrm{ng} / \mathrm{ml}$ ) was significantly higher than that of patients with benign lung disease (mean, $1210.139 \mathrm{ng} / \mathrm{ml}$; median, $1035.900 \mathrm{ng} / \mathrm{ml}$; range, 547.596-2331.167 ng/ml) and normal controls (mean, $1303.369 \mathrm{ng} / \mathrm{ml}$; median, $1194.800 \mathrm{ng} / \mathrm{ml}$; range, 528.200-2140.500 ng/ml) $(\mathrm{P}<0.001$,
Table II. Characteristics of patients.

\begin{tabular}{lrrrr}
\hline & \multicolumn{2}{c}{$\begin{array}{c}\text { Range of } \\
\text { (male/female) }\end{array}$} & $\begin{array}{c}\text { Mean of } \\
\text { the age } \\
\text { (years) }\end{array}$ & $\begin{array}{r}\text { the age } \\
\text { (years) }\end{array}$ \\
\hline Normal controls & 23 & $(16 / 7)$ & $36-77$ & 58.13 \\
Benign lung disease & 17 & $(13 / 4)$ & $34-83$ & 60.94 \\
Lung cancers & 98 & $(68 / 30)$ & $35-82$ & 59.63 \\
Lung cancer I & 17 & $(12 / 5)$ & $42-82$ & 66.06 \\
Lung cancer II & 21 & $(14 / 7)$ & $38-76$ & 58.19 \\
Lung cancer III & 40 & $(24 / 16)$ & $35-79$ & 58.35 \\
Lung cancer IV & 20 & $(18 / 2)$ & $37-75$ & 58.25 \\
Total & 138 & $(97 / 41)$ & $35-83$ & 59.54
\end{tabular}

Stratifying the analysis by American Joint Committee on Cancer stage for lung cancer.

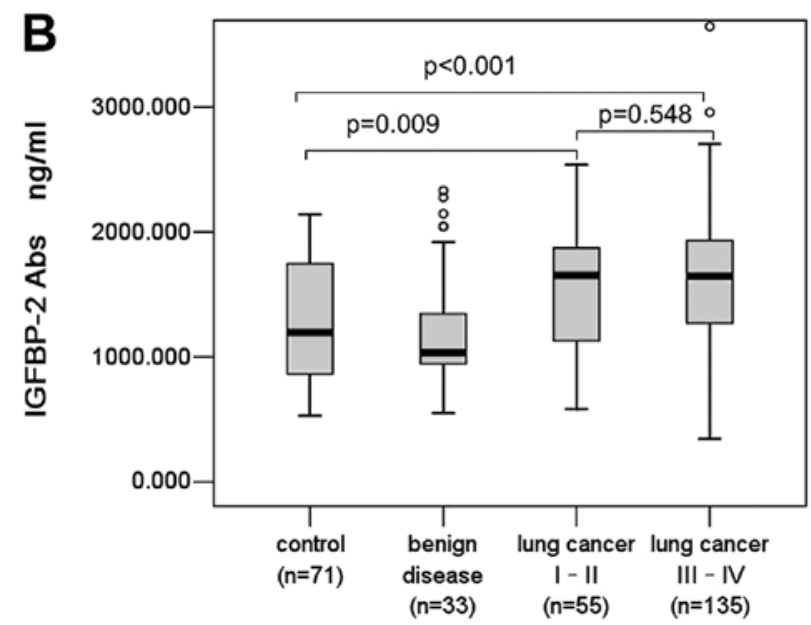

Fig. 1A). However, there was no significant difference between serum anti-IGFBP-2 antibody levels of patients with lung benign disease and normal controls $(\mathrm{P}=0.509$, Fig. 1A).

Li et al (17) demonstrated that anti-IGFBP-2 antibody levels were higher in early cancers than advanced cancers in gliomas and colorectal cancer. When stratifying the analysis by American Joint Committee on Cancer stage for lung cancer, interestingly, a modest difference in anti-IGFBP-2 antibody levels was observed between early cancers and advanced cancers in lung cancer. Patients with lung cancer stage I-II (mean, $1549.671 \mathrm{ng} / \mathrm{ml}$; median, $1651.749 \mathrm{ng} / \mathrm{ml}$ ) did not have an elevated anti-IGFBP-2 antibodies compared to patients with lung cancer stage III-IV (1667.397 ng/ml; median, $1648.400 \mathrm{ng} / \mathrm{ml})(\mathrm{P}=0.548$, Fig. 1B). There was no significant association of the serum levels of anti-IGFBP-2 antibodies in any of the collected histological types $(\mathrm{P}=0.701)$ (data not shown). 

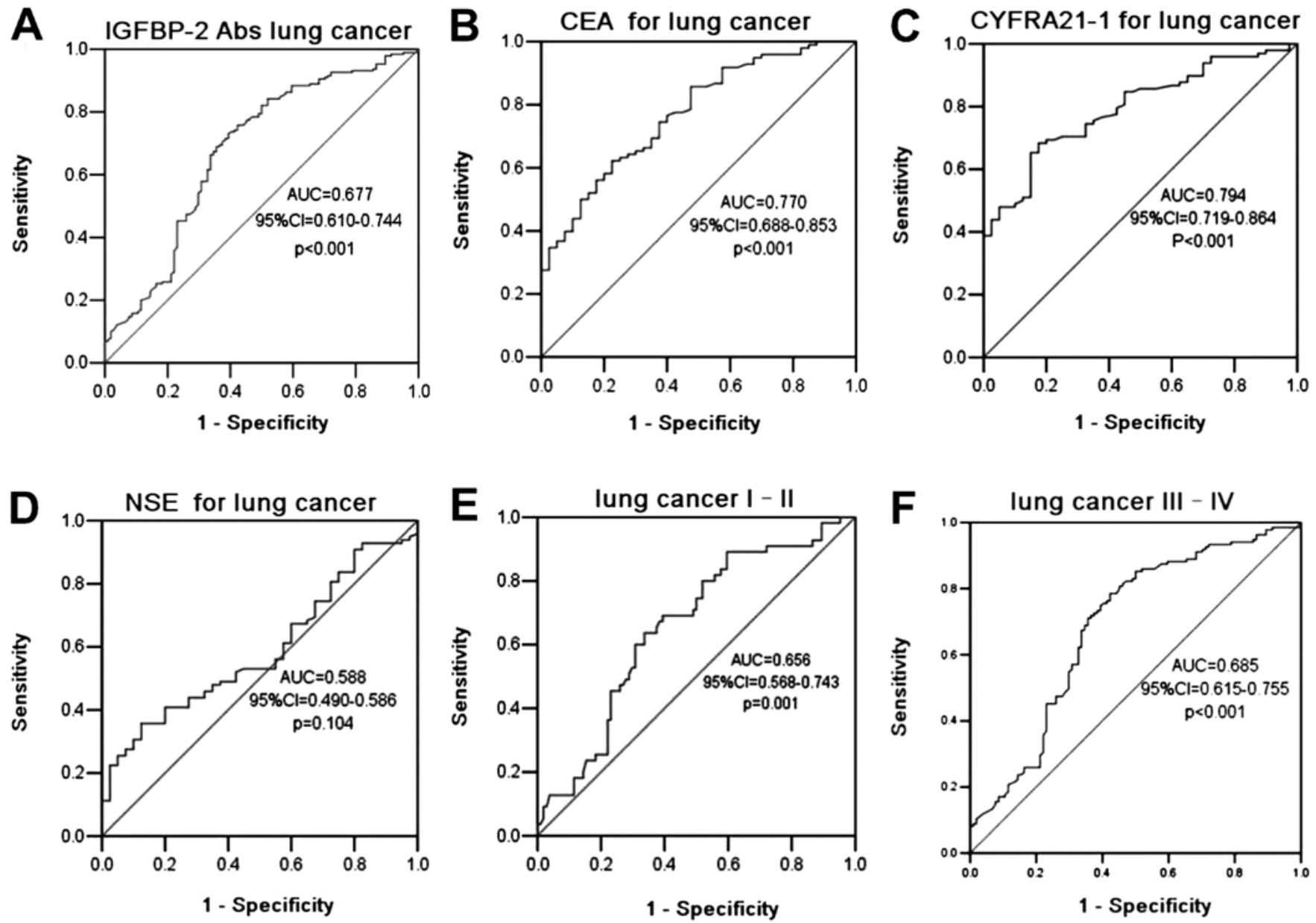

Figure 2. ROC curves of the serum anti-IGFBP-2 antibodies, CEA, CYFRA21-1 and NSE in discriminating between controls and patients with lung cancer (A-D) ROC curves of the serum anti-IGFBP-2 antibodies, CEA, CYFRA21-1 and NSE; (E) ROC curves of the serum anti-IGFBP-2 antibodies in discriminating lung cancer I-II; (F) ROC curves of the serum anti-IGFBP-2 antibodies in discriminating lung cancer III-IV. CI, confidence interval.

Serum anti-IGFBP-2 antibodies as biomarkers for lung cancer diagnosis. ROC curves were constructed between lung cancer and benign lung disease and normal controls. The AUC of using anti-IGFBP-2 antibodies as diagnostic biomarkers for lung cancer was 0.677 (95\% CI=0.610-0.744; $\mathrm{P}<0.0001)$ (Fig. 2A), in contrast to an AUC for CEA, CYFRA21-1 and NSE of 0.770 (95\% CI=0.688-0.853, $\mathrm{P}<0.0001), 0.794$ (95\% CI=0.719-0.864, $\mathrm{P}<0.0001)$ and $0.588(95 \% \mathrm{CI}=0.490-0.586, \mathrm{P}=0.104)$, respectively, for cancer in our patient cohort (Fig. 2A-D). When stratifying lung cancer by tumor stage, the AUC for lung cancer I-II and lung cancer III-IV was $0.656(95 \% \mathrm{CI}=0.568-0.743$; $\mathrm{P}=0.001)$ and 0.685 (95\% $\mathrm{CI}=0.615-0.755 ; \mathrm{P}<0.001)$ (Fig. $2 \mathrm{E}$ and F), respectively, indicating some ability of anti-IGFBP-2 antibodies to diagnose lung cancer. Sensitivity, specificity, and all cutoff values of anti-IGFBP-2 antibody levels were determined using ROC analysis. The anti-IGFBP-2 antibody cutoff values of $1,151.351,1,261.208,1,448.053,1,651.606$, $1,922.826,2,029.312 \mathrm{ng} / \mathrm{ml}$ yielded sensitivities of $80,73.7,61.6$, 49.5, 25.3 and 16.3\%; and specificities of 50, 59.6, 67.3, 71.2, 83.7 and $89.5 \%$, respectively. Based on these data, a level of $1,264.306 \mathrm{ng} / \mathrm{ml}$ (the sum of sensitivity and specificity was the highest) was determined to be the most efficient threshold and we set this level as the cutoff value. The sensitivity of the assay was $73.2 \%$ and the specificity $60.6 \%$, and the positive and nega- tive predictive values were 77.2 and $55.3 \%$, respectively. The sensitivity of serum anti-IGFBP-2 antibodies in the detection of lung cancer was higher $(73.2 \%)$ than that of CEA $(45.9 \%)$, CYFRA21-1 (65.3\%), or NSE (50\%), $(\mathrm{P}<0.001, \mathrm{P}=0.166$ and $\mathrm{P}<0.001$, respectively) although the differences were not significant $(\mathrm{P}<0.001, \mathrm{P}=0.166$ and $\mathrm{P}<0.001$, respectively).

Combination of serum IGFBP-2 and anti-IGFBP-2 antibodies can increase the efficacy of cancer diagnosis. In this study, we also detected serum IGFBP-2 levels in 98 patients with lung cancer, 17 patients with benign lung disease, and 23 normal controls, and found that serum IGFBP-2 levels were significantly elevated in lung cancer patients (mean, $1,304.273 \mathrm{ng} / \mathrm{ml}$; median, $1,225.109 \mathrm{ng} / \mathrm{ml}$; range, 265-3,584.674 $\mathrm{ng} / \mathrm{ml}$ ) compared with controls (749.428, 777.228, 51.944-1,384.217 ng/ml) $(\mathrm{P}<0.0001$, Fig. 3A). Serum IGFBP-2 levels in patients with lung cancer were higher than that of benign lung disease $(1,036.015,766.304$, 209.185-2,885.543 ng/ml), but the difference was not significant $(\mathrm{P}=0.148$, Fig. 3A). There was no significant difference between lung cancer I-II and lung cancer III-IV either ( $\mathrm{P}=0.236$, Fig. $3 \mathrm{~B})$. We conducted ROC curve analyses using serum IGFBP-2 levels in discriminating between patients and controls (Fig. 3C). The AUC of using IGFBP-2 as diagnostic biomarker for lung cancer was $0.608(95 \% \mathrm{CI}=0.504-0.712, \mathrm{p}=0.047)$, the sensitivity and 

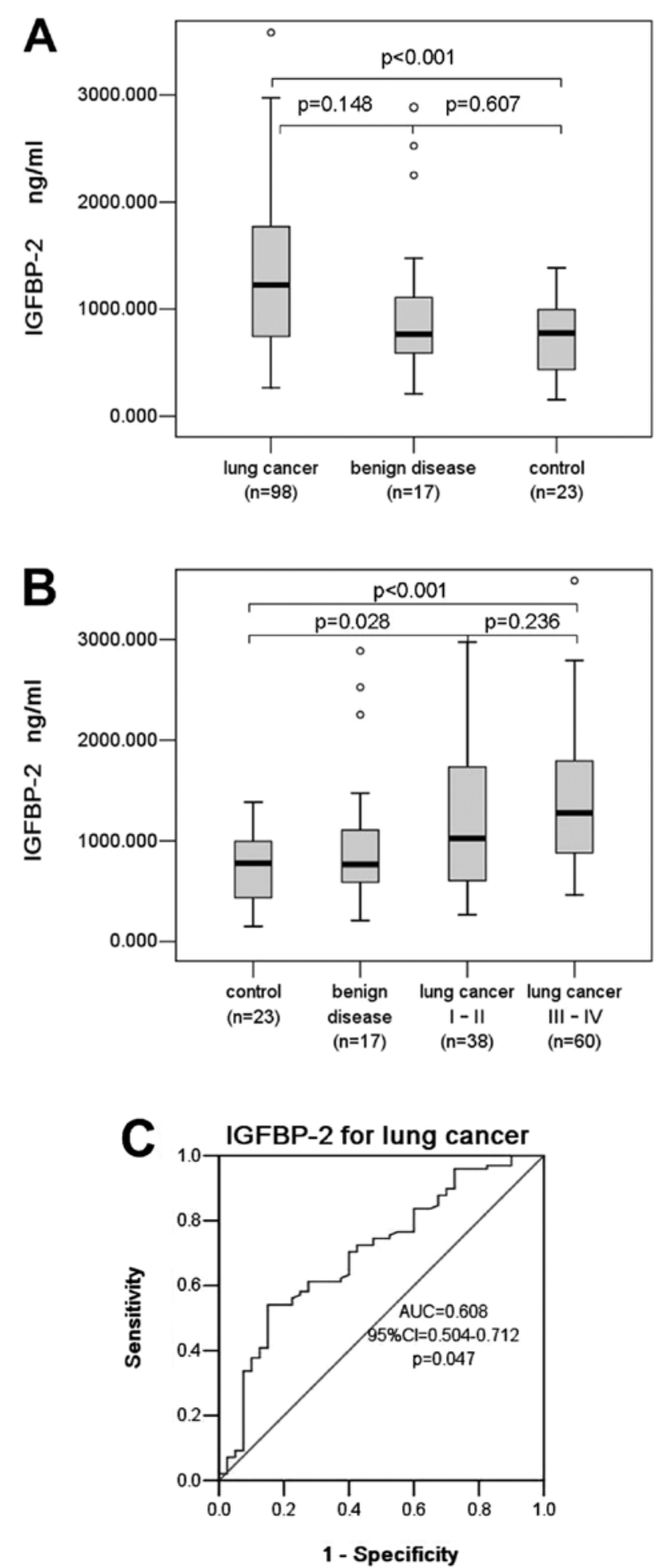

Figure 3. Diagnostic values of combined serum IGFBP-2 and anti-IGFBP-2 antibodies in distinguishing between controls and patients with lung cancer. (A and B) Serum IGFBP-2, comparisons among normal controls, benign lung disease and patients with lung cancer, and substages. (C) ROC curves of using serum IGFBP-2 in discriminating lung cancer. Median levels of serum autoantibodies to IGFBP-2 and interquartile ranges are illustrated by box plot.

specificity were 54.1 and $72.5 \%$, respectively, with the cutoff value of $1,173.033 \mathrm{ng} / \mathrm{ml}$. We found that the combination of serum IGFBP-2 and anti-IGFBP-2 antibodies can augment the
Table III. Characteristics of patients for follow-up.

\begin{tabular}{rrrcc}
\hline Patients & Age/sex & Stage & Pathology & Therapy \\
\hline 40 & $62 / \mathrm{M}$ & II B & Squamous & Radical procedure \\
74 & $45 / \mathrm{F}$ & II A & Adeno & Radical procedure \\
79 & $55 / \mathrm{M}$ & III A & Adeno & Radical procedure \\
161 & $41 / \mathrm{F}$ & II A & Adeno & Radical procedure \\
181 & $62 / \mathrm{M}$ & III A & Adeno & Radical procedure \\
299 & $48 / \mathrm{M}$ & III B & Adeno & Radical procedure \\
41 & $56 / \mathrm{M}$ & III A & Squamous & Chemotherapy (NP) \\
43 & $62 / \mathrm{F}$ & III B & Adeno & Chemotherapy (TP) \\
298 & $41 / \mathrm{M}$ & IV & Adeno & Chemotherapy (TP)
\end{tabular}

Squamous, squamous cell carcinoma; adeno, adenocarcinoma; NP, vinorelbine and cisplatin (vinorelbine for $25 \mathrm{mg} / \mathrm{m}^{2}$ and cisplatin for $75 \mathrm{mg} / \mathrm{m}^{2}$ ); TP, docetaxel and cisplatin (docetaxel for $75 \mathrm{mg} / \mathrm{m}^{2}$ and cisplatin for $75 \mathrm{mg} / \mathrm{m}^{2}$ ).

discriminative power for lung cancer with the sensitivity of $85.7 \%$ and the specificity of $57.5 \%$.

Relationship of serum anti-IGFBP-2 antibodies and tumor IGFBP-2 expression in lung cancer. In this study, we also examined IGFBP-2 expression in 23 lung cancer tissue sections (Fig. 4), and found 69.6\% (16/23) of the lung cancer specimens had low $(43.5 \%)$ to high $(26.1 \%)$ IGFBP-2 expression, and $82.6 \%(19 / 23)$ of the tissue specimens had anti-IGFBP-2 antibody levels above the cut-off value of $1,264.306 \mathrm{ng} / \mathrm{ml}$ (data were not shown). Interestingly, we did not find a correlation between serum anti-IGFBP-2 antibody level and tumor IGFBP-2 expression level in lung cancer.

Follow-up of serum levels of anti-IGFBP-2 antibodies in lung cancer. In order to determine whether concentration of antiIGFBP-2 antibodies would change with the clinical treatment, a follow-up study has been performed. In the current study, 6 patients were observed, and serum samples were collected from these patients at 3-4 weeks after tumor resection, and for some patients samples were also collected after 1-2 cycles of postoperative chemotherapy. Data from three patients with chemotherapy instead of surgical resection were also analyzed (Table III).

Anti-IGFBP-2 antibody level before operation was elevated in all of the 6 patients (100\%). Interestingly, antibody level was decreased in 4 patients $(66.7 \%)$ after 3-4 week treatment, and only one patient $(16.7 \%)$ has an elevated antibody level, and one patient's antibody level was not changed. We also found that anti-IGFBP-2 antibody levels in all patients were reduced with the time progression (Fig. 5B).

In the follow-up observation of three patients who underwent chemotherapy, levels of anti-IGFBP-2 antibodies were elevated in all of the 3 patients $(100 \%)$ at diagnosis, levels decreased in 2 patients $(66.7 \%)$ after 1 cycle chemotherapy, and slightly elevated in one patient whose disease progressed at that time. For patient no. 41 , who developed a liver metastasis after 2 cycles of chemotherapy of vinorelbine and cisplatin, the antibody levels were also decreased when the disease progressed (Fig. 5A). 

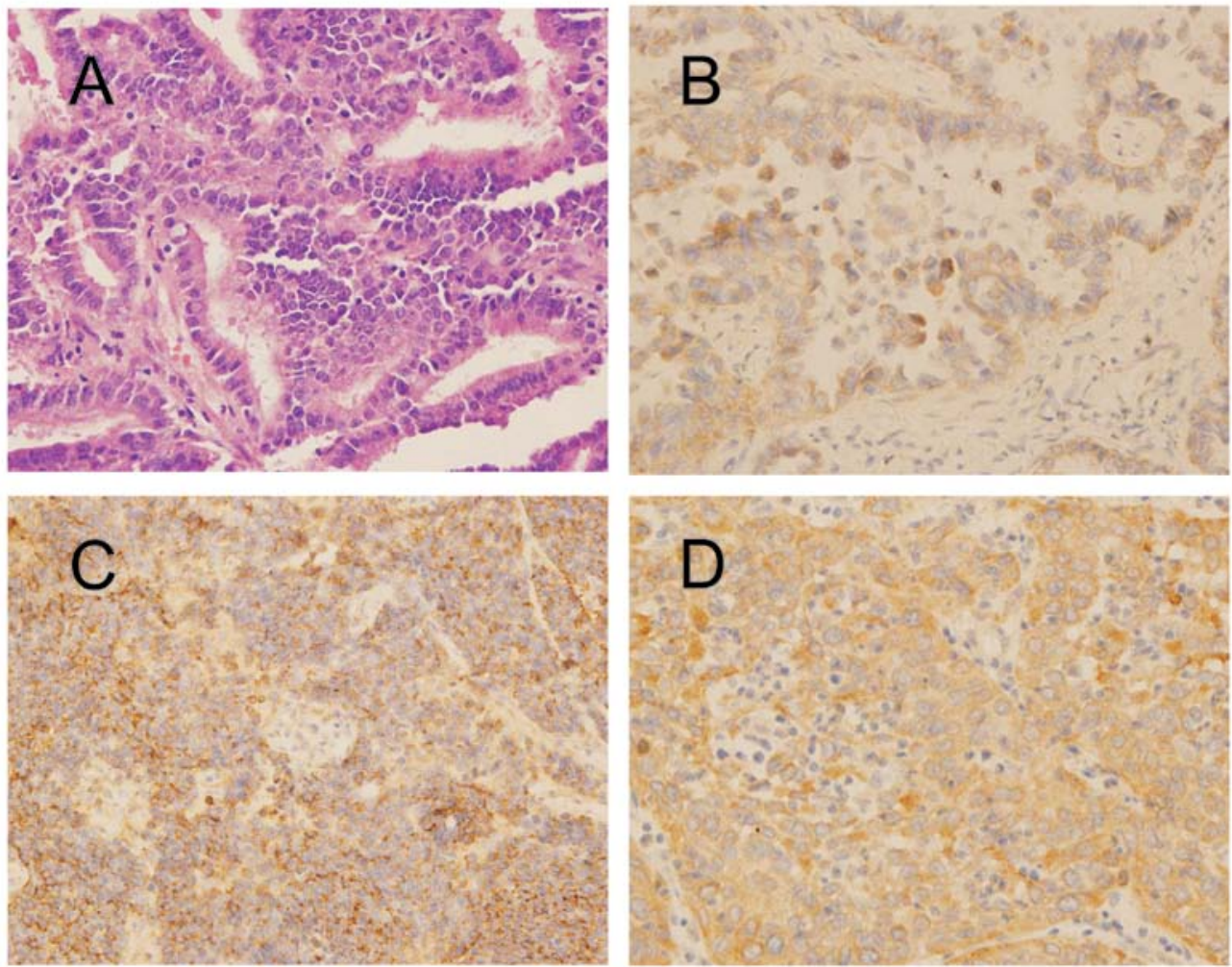

Figure 4. IGFBP-2 expression in lung cancer tissue sections. (A) Lung cancer tissue, Hematoxylin and eosin; (B) IGFBP-2 expression in lung adenocarcinoma; (C) IGFBP-2 expression in SCLC; (D) IGFBP-2 expression in lung squamous cell carcinoma; magnification, $\mathrm{x} 400$.

A

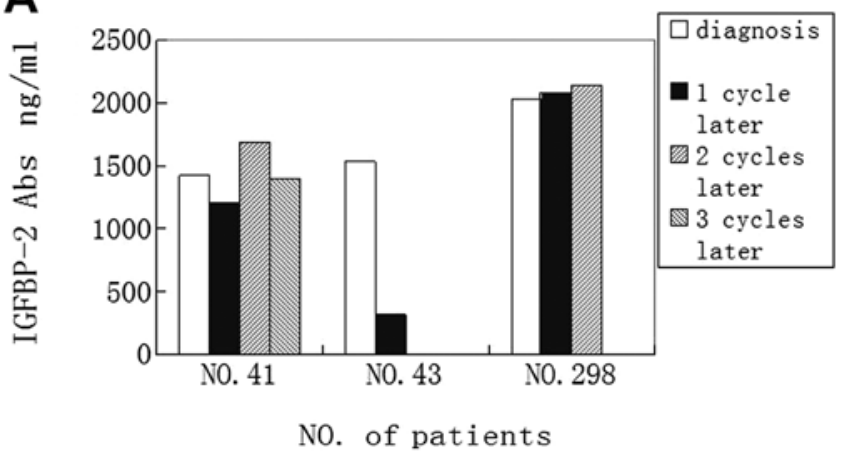

B

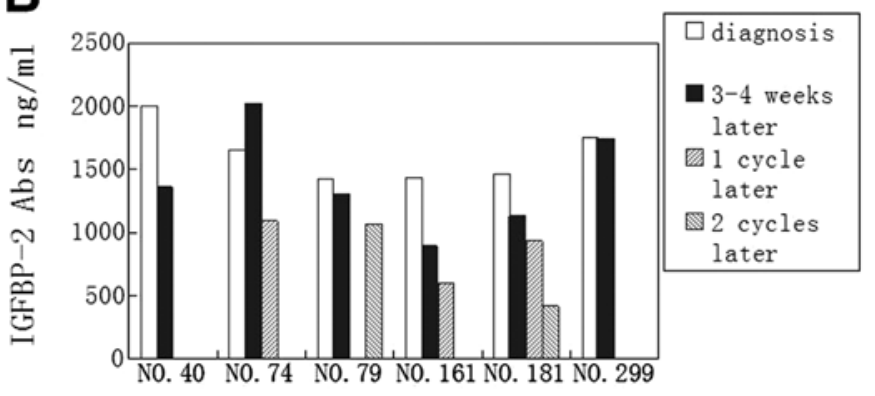

NO. of patients

Figure 5. (A) Three patients with unresectable disease who underwent chemotherapy during follow-up; PD, progressive disease. Patient no. 41 developed liver metastasis after 2 cycles chemotherapy of vinorelbine and cisplatin, and as patient no. 298, the tumor size increased after 1 cycle of docetaxel and cisplatin chemotherapy. (B) Levels of anti-IGFBP-2 antibodies in 6 sera from patients with lung cancer before and after radical procedure and during follow-up. The sample of 1 cycle postoperative chemotherapy of patients no. 79 was not collected, and for patient nos. 40 and 299 , there were only samples of before and after radical procedure.

\section{Discussion}

Previous studies have indicated that IGFBPs are modulators of IGF signaling through sequestration of IGFs. Soluble and membrane-associated IGFBP-2 directly binds to proteoglycans and integrins $(18,19)$, suggesting that IGFBP-2 may be a negative or positive regulator of cell adhesion, migration, and invasion in an IGF-independent manner (20-24). In the same way, IGFBP-2 positively or negatively regulates cell growth and survival in certain types of cancers in both of in vitro and in vivo studies $(20-22,25,26)$. Thus, increased IGFBP-2 confers advantage or disadvantage for tumor growth, depending on cell type and physiological conditions.

Despite these two opposite effects of IGFBP-2 on the biological behavior of cancers, studies on biochemistry and molecular pathology have demonstrated that IGFBP-2 is overexpressed in a wide variety of human malignancies, including lung cancer, glioma, prostate cancer, colorectal cancer, ovarian cancer, adrenocortical tumor, breast cancer and leukemia. Importantly, IGFBP-2 is frequently overexpressed in advanced cancers, suggesting that it may be involved in the metastatic process. Serum IGFBP- 2 can be used for prediction of chemo- 
therapy response and prognosis in ovarian cancer and acute lymphoblastic leukemia (27). Some other studies have also demonstrated that IGFBP-2 can be considered as a regulator of phosphatidylinositol 3-kinase (PI3K)/Akt/PTEN to promote tumor progression $(19,21,28)$ and also as a p53 target (29). Grimberg et al (29) have reported that loss of IGFBP-2 can inhibit the ability of p53 to further activate extracellular signalregulated kinase (ERK)1 by IGF-I. Migita et al (30) also found that intracellular IGFBP-2 regulates caspase-3 expression and contributes to the inhibitory effect on apoptosis independent of IGF in lung adenocarcinoma. Therefore, IGFBP-2 may offer a novel therapeutic target and serve as an anti-apoptotic biomarker for lung adenocarcinoma.

As mentioned above, the autoantibodies against TAAs can be used as reporters in identifying aberrant cellular mechanisms in tumorigenesis and also served as immunodiagnostic markers for cancer detection. Our results provide the first evidence that the serum levels of anti-IGFBP-2 antibodies in patients with lung cancer are higher than that of patients with benign lung diseases and normal controls. The majority of patients with lung cancer present with advanced disease because there are no symptoms at the early stage. Although CEA, CYFRA21-1 and NSE are commonly used markers in lung cancer diagnosis, none of these markers is optimal. The finding in this study may provide a potential marker of anti-IGFBP-2 antibody in diagnosing lung cancer. The sensitivity of the assay was $73.2 \%$ and the specificity $60.6 \%$ with the cutoff value of $1,264.306 \mathrm{ng} / \mathrm{ml}$, which is better than CEA, CYFRA21-1 and NSE in lung cancer detection.

A recently published paper demonstrated that serum antiIGFBP-2 antibody levels were significantly elevated in early cancer compared to advanced cancers in gliomas and colorectal carcinoma (17). Interestingly, our study suggested different results in lung cancer, indicating a different immunogenicity of IGFBP-2 in patients with lung cancer compared to patients with gliomas and colorectal carcinoma. It may be related to the microenvironment of the various tumors (31) and immunosuppressive mechanisms induced by tumor cells (32) and also a different role of TAAs in tumor development.

Due to the high specificity of the autoantibodies to TAAs in cancer, anti-TAA antibodies have been generally considered as reliable biomarkers in cancer. At the cut-offs of 1,264.306 and $2,029.312 \mathrm{ng} / \mathrm{ml}$ of anti-IGFBP-2 antibodies, the specificity for lung cancer were 60.6 and $89.5 \%$, respectively. It is well known that if only one anti-TAA antibody is used as tumor marker, the sensitivity is about $10-20 \%$. As described above, IGFBP-2 is frequently overexpressed in advanced cancers and can be used for prediction of chemotherapy response and prognosis in some malignancy. When serum IGFBP-2 and anti-IGFBP-2 antibodies were detected simultaneously, the sensitivity of the assay was raised to $85.7 \%$, and the specificity was $57.5 \%$ indicating that use of both serum IGFBP2 and anti-IGFBP-2 antibody can increase the diagnostic efficacy in lung cancer.

Our study also found that most of patient serum levels of anti-IGFBP-2 antibodies (66.7\%) were decreased after surgical operation and chemotherapy. When the tumor size was increasing or the patient was developing metastasis, the serum levels of anti-IGFBP-2 antibodies were increased, suggesting a role for anti-IGFBP-2 antibodies in assessing response to therapy in lung cancer.
The weakness of the study is that the healthy controls did not receive a bronchoscopy, possibly leading to misclassification of the study subjects, and there was also the relatively small sample size, especially for patients with benign lung diseases. Further studies with larger sample size from different type of cancer will be performed to confirm and validate whether anti-IGFBP-2 antibodies can be also used as a diagnostic marker in other type of cancer.

\section{Acknowledgements}

We thank Huixun Ren at Xi'an Jiaotong University School of Medicine for his help. The study was supported by the Clinical Innovation Funds of The First Affiliated Hospital of XJTU (grant no. 11ZD05).

\section{References}

1. Jemal A, Siegel R, Ward E, Murray T, Xu J, Smigal C and Thun MJ: Cancer statistics, 2006. CA Cancer J Clin 56: 106-130, 2006.

2. Woodward RM, Brown ML, Stewart ST, Cronin KA and Cutler DM: The value of medical interventions for lung cancer in the elderly: results from SEER-CMHSF. Cancer 110: 2511-2518, 2007.

3. Ernst A, Anantham D, Eberhardt R, Krasnik M and Herth FJ: Diagnosis of mediastinal adenopathy-real-time endobronchial ultrasound guided needle aspiration versus mediastinoscopy. J Thorac Oncol 3: 577-582, 2008.

4. Nakashima A, Murakami Y, Uemura K, et al: Usefulness of human telomerase reverse transcriptase in pancreatic juice as a biomarker of pancreatic malignancy. Pancreas 38: 527-533, 2009.

5. Ghaneh P, Greenhalf W, Humphreys M, et al: Adenovirusmediated transfer of p53 and p16 (INK4a) results in pancreatic cancer regression in vitro and in vivo. Gene Ther 8: 199-208, 2007.

6. Soussi T: p53 antibodies in the sera of patients with various types of cancer. Cancer Res 60: 1777-1788, 2010.

7. Looi K, Megliorino R, Shi FD, Peng XX, Chen Y and Zhang JY: Humoral immune response to p16, a cyclin-dependent kinase inhibitor in human malignancies. Oncol Rep 16: 1105-1110, 2006.

8. Zhang JY, Chan EK, Peng XX and Tan EM: A novel cytoplasmic protein with RNA-binding motifs is an autoantigen in human hepatocellular carcinoma. J Exp Med 189: 1101-1110, 1999.

9. Park KH, Gad E, Goodell V, et al: Insulin-like growth factorbinding protein-2 is a target for the immunomodulation of breast cancer. Cancer Res 68: 8400-8409, 2008.

10. Lin Y, Jiang T, Zhou K, et al: Plasma IGFBP-2 levels predict clinical outcomes of patients with high-grade gliomas. Neuro Oncol 11: 468-476, 2009.

11. Miraki-Moud F, Jenkins PJ, Fairclough PD, et al: Increased levels of insulin-like growth factor binding protein-2 in sera and tumours from patients with colonic neoplasia with and without acromegaly. Clin Endocrinol (Oxf) 54: 499-508, 2001.

12. Liou JM, Shun CT, Liang JT, et al: Plasma insulin-like growth factor-binding protein-2 levels as diagnostic and prognostic biomarker of colorectal cancer. J Clin Endocrinol Metab 95: 1717-1725, 2010.

13. Shariat SF, Lamb DJ, Kattan MW, et al: Association of preoperative plasma levels of insulin-like growth factor I and insulin-like growth factor binding proteins-2 and -3 with prostate cancer invasion, progression, and metastasis. J Clin Oncol 20: 833-841, 2002 .

14. Wang H, Rosen DG, Wang H, Fuller GN, Zhang W and Liu J: Insulin-like growth factor-binding protein 2 and 5 are differentially regulated in ovarian cancer of different histologic types. Mod Pathol 19: 1149-1156, 2006.

15. Busund LT, Richardsen E, Busund R, Ukkonen T, Bjørnsen T, Busch C and Stalsberg H: Significant expression of IGFBP2 in breast cancer compared with benign lesions. J Clin Pathol 58: $361-366,2005$ 
16. Baron-Hay S, Boyle F, Ferrier A and Scott C: Elevated serum insulin-like growth factor binding protein-2 as a prognostic marker in patients with ovarian cancer. Clin Cancer Res 10: 1796-1806, 2004.

17. Li Y, Jiang T, Zhang J, et al: Elevated serum antibodies against insulin-like growth factor-binding protein-2 allow detecting early-stage cancers: evidences from glioma and colorectal carcinoma studies. Ann Oncol 23: 2415-2422, 2012.

18. Pereira JJ, Meyer T, Docherty SE, Reid HH, et al: Bimolecular interaction of insulin-like growth factor (IGF) binding protein-2 with alphavbeta3 negatively modulates IGF-I-mediated migration and tumor growth. Cancer Res 64: 977-984, 2004.

19. Wang GK, $\mathrm{Hu} \mathrm{L}$, Fuller GN and Zhang W: An interaction between insulin-like growth factor-binding protein 2 (IGFBP2) and integrin alpha5 is essential for IGFBP2-induced cell mobility. J Biol Chem 281: 14085-14091, 2006.

20. Hoeflich A, Reisinger R, Lahm H, et al: Insulin-like growth factor-binding protein 2 in tumorigenesis: protector or promoter. Cancer Res 61: 8601-8610, 2001.

21. Lee EJ, Mircean C, Shmulevich I, et al: Insulin-like growth factor binding protein 2 promotes ovarian cancer cell invasion. Mol Cancer 4: 7, 2005.

22. Miyake H, Hara I, Yamanaka K, Muramaki M, Gleave M and Eto $\mathrm{H}$ : Introduction of insulin-like growth factor binding protein-2 gene into human bladder cancer cells enhances their metastatic potential. Oncol Rep 13: 341-345, 2005.

23. Schütt BS, Langkamp M, Rauschnabel U, Ranke MB and Elmlinger MW: Integrin-mediated action of insulin-like growth factor binding protein-2 in tumor cells. J Mol Endocrinol 32: 859-868, 2004

24. Hoeflich A, Reisinger R, Schuett BS, et al: Peri/nuclear localization of intact insulin-like growth factor binding protein-2 and a distinct carboxyl-terminal IGFBP-2 fragment in vivo. Biochem Biophys Res Commun 324: 705-710, 2004.
25. Hoeflich A, Fettscher O, Lahm H, et al: Overexpression of insulin-like growth factor-binding protein-2 results in increased tumorigenic potential in Y-1 adrenocortical tumor cells. Cancer Res 60: 834-838, 2000.

26. Chatterjee S, Park ES and Soloff MS: Proliferation of DU145 prostate cancer cells is inhibited by suppressing insulin-like growth factor binding protein-2. Int J Urol 11: 876-884, 2004.

27. Vorwerk P, Mohnike K, Wex H, Röhl FW, Zimmermann M, Blum WF and Mittler U: Insulin-like growth factor binding protein-2 at diagnosis of childhood acute lymphoblastic leukemia and the prediction of relapse risk. J Clin Endocrinol Metab 90: 3022-3027, 2005.

28. Mehrian-Shai R, Chen CD, Shi T, et al: Insulin growth factorbinding protein 2 is a candidate biomarker for PTEN status and PI3K/Akt pathway activation in glioblastoma and prostate cancer. Proc Natl Acad Sci USA 104: 5563-5568, 2007.

29. Grimberg A, Coleman CM, Shi Z, Burns TF, MacLachlan TK, Wang W and El-Deiry WS: Insulin-like growth factor factor binding protein-2 is a novel mediator of p53 inhibition of insulin-like growth factor signaling. Cancer Biol Ther 5: 1408-1414, 2006.

30. Migita T, Narita T, Asaka R, et al: Role of insulin-like growth factor binding protein 2 in lung adenocarcinoma: IGF-independent antiapoptotic effect via caspase-3. Am J Pathol 176: 1756-1766, 2010.

31. Lubin R, Schlichtholz B, Teillaud JL, Garay E, Bussel A and Wild CP: p53 antibodies in patients with various types of cancer assay, identification, and characterization, Clin Cancer Res 1: 1463-1469, 1995.

32. Comtesse N, Zippel A, Walle S, et al: Complex humoral immune response against a benign tumor: frequent antibody response against specific antigens as diagnostic targets. Proc Natl Acad Sci USA 102: 9601-9606, 2005. 